\title{
Hybrid repair of type A acute aortic dissections with the Lupiae technique: Ten-year results
}

\author{
Giampiero Esposito, MD, Giangiuseppe Cappabianca, MD, Samuele Bichi, MD, Antonio Cricco, MD, \\ Giovanni Albano, MD, and Angelo Anzuini, MD
}

\begin{abstract}
Objectives: Replacing the ascending aorta and the arch in patients with type A acute aortic dissection achieves good short-term results, but several patients are left with distal intimal tears or a patent false lumen in the descending aorta. In this series, we report the 10-year experience with the Lupiae technique, a hybrid aortic repair technique for patients with type A acute aortic dissection.
\end{abstract}

Methods: From 2003 to 2013, 89 patients with type A acute aortic dissections underwent replacement of the ascending aorta, the arch, and the rerouting of the neck vessels on the ascending aorta, creating a proximal Dacron landing zone for a completion with thoracic endovascular aortic repair if necessary.

Results: In-hospital mortality was $8.9 \%$. In 16 patients, the false lumen healed spontaneously, whereas the remaining 65 patients underwent thoracic endovascular aortic repair. One patient died after thoracic endovascular aortic repair. Eighty patients were followed up. Complete thrombosis of the false lumen was obtained in $93.8 \%$ of patients. The median follow-up was $46 \pm 35$ months. Overall 8-year survival was $93.7 \% \pm 5 \%, 100 \%$ for patients with spontaneously healed residual false lumen after just type A acute aortic dissection repair and $92.3 \% \pm 7.7 \%$ for patients who underwent thoracic endovascular aortic repair after type A acute aortic dissection repair. In 10 years, 1 patient underwent a reoperation on the distal aorta $(1.25 \%)$.

Conclusions: The availability of a Dacron landing zone on the distal ascending aorta after type A acute aortic dissection repair allows the exclusion, with a thoracic endovascular aortic repair, of any residual intimal tear refilling a patent false lumen. This approach seems to be associated with a high probability of false lumen thrombosis and low rates of reoperations on the distal aorta. (J Thorac Cardiovasc Surg 2015;149:S99-104)

In patients with type A acute aortic dissection (TAAAD), the aim of the operation is to restore the blood flow into the true lumen and to avoid or treat otherwise lethal complications, such as pericardial tamponade, coronary dissection, and acute aortic regurgitation.

The resection of the intimal tear also is a goal of repair procedures for TAAAD, because this should promote the thrombosis of the residual false lumen. This assumption has led many groups toward a more aggressive approach replacing the arch when a tear is identified at this level. The results are controversial, ${ }^{1,2}$ probably because the presence of 1 or multiple distal tears in the descending aorta can still sustain the blood flow in the residual false lumen.

Since 1994, the fate of the residual false lumen after TAAAD repairs has been evaluated in 24 studies identifying

From the Department of Cardiac Surgery, Humanitas Gavazzeni Hospital, Bergamo, Italy.

Disclosures: Authors have nothing to disclose with regard to commercial support.

Read at The American Association for Thoracic Surgery Aortic Symposium,

New York, New York, April 24-25, 2014.

Received for publication April 24, 2014; revisions received July 14, 2014; accepted for publication July 21, 2014; available ahead of print Sept 22, 2014.

Address for reprints: Giangiuseppe Cappabianca, MD, Humanitas Gavazzeni

Hospital, Via Mauro Gavazzeni, 21, 24125 Bergamo, Italy (E-mail: giangi.

cappabianca@gmail.com).

$0022-5223 / \$ 36.00$

Copyright (C) 2015 by The American Association for Thoracic Surgery

http://dx.doi.org/10.1016/j.jtcvs.2014.07.099 the persistence of a nonresected intimal tear, the patency or the partial thrombosis of the false lumen, an already dilated descending aorta, or a dominant false lumen compressing the true lumen as risk factors for delayed aneurysmal expansion, reoperation, and worse long-term survival. ${ }^{3-26}$

We developed a hybrid repair for TAAAD, the Lupiae technique, consisting of a first surgical step replacing the ascending aorta and the arch while rerouting the neck vessels on the proximal ascending aorta. This creates a Dacron landing zone in Criado zone 0 , which allows us to perform a thoracic endovascular aortic repair (TEVAR) as the second step to exclude any residual intimal tear refilling the false lumen.

The short and midterm results of the Lupiae technique in patients with TAAAD have been reported, ${ }^{27}$ showing a low in-hospital mortality and low stroke and spinal cord injury rates. In this article, we focus instead on the long-term results achieved with this technique.

\section{METHODS}

From October 2003 to October 2013, 89 consecutive patients underwent the repair of TAAAD using the Lupiae technique. Ethics approval for this study was granted by our institutional research ethics board. Exclusion criteria for this procedure were the arrival to the operating room with cardiac arrest or the presence of severe neurologic damages preoperatively. In this series, all patients had a TAAAD extending at least to the midportion of the descending aorta. All patients underwent at least the replacement of the ascending aorta and the aortic arch, and the rerouting of 2 (innominate 


\section{Abbreviations and Acronyms \\ $\mathrm{CT}=$ computed tomography \\ LSA $=$ left subclavian artery \\ TAAAD $=$ type $\mathrm{A}$ acute aortic dissection \\ TEVAR $=$ thoracic endovascular aortic repair}

artery and left carotid) or all 3 neck vessels on the proximal ascending aorta. The technical aspects of the Lupiae technique in TAAAD have been described. ${ }^{27} \mathrm{~A}$ schematic representation of the Lupiae technique is shown in Figure 1.

Through the years, a few modifications have been implemented. During the first 2 years, a custom-made Dacron graft was constructed anastomosing to a 28- to 34-mm Dacron straight graft three 8-mm Dacron grafts in line with the superior aspect and $2 \mathrm{~cm}$ above the proximal end of the main graft. Since March 2006, the Vascutek Lupiae graft (Vascutek Terumo, Renfrewshire, Scotland, UK), designed specifically for this procedure, became available. The main features of this graft were the presence of a bovine trunk at the proximal end dividing into 3 branches for the neck vessels and a fourth branch opposite to the bovine trunk used to resume the antegrade perfusion once the distal aortic anastomosis was completed. The choice of a bovine trunk, oriented vertically between the superior vena cava and the aorta, reduced the space occupied by 3 single branches on the main graft, increasing the space available as a landing zone and reducing the chances of branch compression once the chest was closed. The bovine trunk and the fourth branch also were marked with radiopaque dots to identify them, while under fluoroscopy, during TEVAR.

The extent of aortic arch resection was progressively reduced, shifting from resecting as much arch as possible to resecting the proximal aorta, rerouting the neck vessel, and creating a greater than $2.5-\mathrm{cm}$ Dacron landing zone. The distal anastomosis initially was performed beyond the origin of the left subclavian artery (LSA). Subsequently, provided that any obvious tear in the arch was resected and all 3 neck vessels were rerouted on the ascending aorta, the distal anastomosis was located between the left carotid artery and the LSA. Eventually, in patients in whom the LSA could not be reached and rerouted because it was too lateral and deep in the chest, this was left on the native arch and a carotid-subclavian bypass was performed before the TEVAR.

Perfusion strategies have evolved through the years. Antegrade perfusion was adopted in all the patients with TAAAD, but from 2003 to 2005 , the right subclavian artery was isolated through a separate incision and cannulated with the interposition of an 8-mm Dacron graft. In 2005, the cannulation site was moved centrally by anastomosing end-to-side an 8-mm Dacron graft to the distal innominate artery. In the few cases in which the innominate artery was distally dissected, the right axillary artery or the apex of the left ventricle was used as an alternative cannulation site. Therefore, in all the patients, unilateral selective antegrade cerebral perfusion via the right subclavian or directly the innominate artery was used. From 2005, a second 8-mm Dacron graft was anastomosed to the LSA and connected to a separate perfusion line that was switched on during the distal circulatory arrest at $10 \mathrm{~mL} / \mathrm{kg} / \mathrm{min}$ to provide a better blood supply, via the left vertebral artery, to the brain and spinal cord. Perfusion temperatures ranged from $20^{\circ} \mathrm{C}$ in 2003 to $28^{\circ} \mathrm{C}$ in 2005 to $30^{\circ} \mathrm{C}$ in 2010 , particularly when no repair on the root was planned and the crossclamp was expected to be shorter.

\section{Computed Tomography Scan Assessment}

In case of malperfusion (spinal, visceral, or lower limbs) postoperatively, an urgent computed tomography (CT) scan \pm TEVAR was performed. Otherwise, patients underwent CT of the aorta 4 weeks after the operation. The patency and size of the residual false lumen together with the diameter of the descending aorta were evaluated.
Since 2011, given the availability of a more accurate imaging with electrocardiogram-gated CT scans, the presence and position of the distal intimal tears also were evaluated and used to determine the distal extension of TEVARs.

We considered the residual false lumen "unstable" when at least 2 of these 3 radiologic signs were found: (1) complete patency or partial thrombosis of the residual false lumen; (2) presence of a dominant false lumen greater than $22 \mathrm{~mm}$, prevailing on the true lumen; and (3) a dilatation of the descending aorta greater than $46 \mathrm{~mm}$. Patients with an "unstable" false lumen underwent a TEVAR. Patients with a thrombosed, nondominant false lumen and a descending aorta less than $46 \mathrm{~mm}$ were considered "healed" and followed up on a yearly basis.

Patients presenting only 1 of the 3 risk factors were considered more stable and received a repeated CT scan in 6 months. If the false lumen was still patent or partially thrombosed or the diameter of the descending aorta was increased from the previous scan, they underwent TEVAR. Otherwise, they were followed up on a yearly basis. Figure 2 summarizes the management of these patients.

\section{Endovascular Step}

The access to the femoral arteries was surgical. After systemic heparinization, 1 or multiple self-expanding nitinol-framed stent-grafts (Valiant, Medtronic Inc, Santa Rosa, Calif; Jotec E-Vita, Jotec GmBH, Hechingen, Germany) were deployed. The first endovascular stent was landed on the Dacron landing zone created during the TAAAD repair. If the position of the intimal tear was known, the main purpose of the procedure was to exclude it. When this was unknown or multiple tears were present, the distal extension of the flap was used as a reference, with the coeliac trunk as the lowest limit. CT of the aorta was repeated in 4 weeks to evaluate the thrombosis of the residual false lumen and the presence of endoleaks.

\section{Follow-up}

The follow-up ranged from 6 months to 10 years. The median follow-up was $46 \pm 35$ months. Eighty patients were followed up; $53(66 \%)$ were seen on a regular basis in outpatient clinic. For the remaining patients, data on survival and reoperations were retrieved by telephoning the patients or their general practitioner. Follow-up completeness was 100\%.

\section{Statistical Analysis}

Continuous variables are presented as mean \pm standard deviation. Categoric variables are presented as number and percentage. The Kaplan-Meier product limit method was used to calculate survival probability. Stat-View 5.0 (SAS Institute Inc, Cary, NC) was used for survival calculations.

\section{RESULTS}

Preoperative characteristics are summarized in Table 1. The most common presentation was chest, abdominal, or back pain, and a preoperative cerebrovascular accident was diagnosed in 13 patients $(14.6 \%)$. Only 1 patient had Marfan syndrome. In $79.7 \%$ of patients, the dissection flap extended to the abdominal aorta.

Intraoperative data are summarized in Table 2. Of 21 patients with severe aortic regurgitation, 11 had a root replacement and 10 had a valve-sparing procedure (Table 2). The intimal tear was most frequently found and resected in the arch. The LSA was rerouted intraoperatively in $42 \%$ of patients.

Eight patients died after the surgery $(8.9 \%)$. One patient died intraoperatively as a result of the rupture of the 

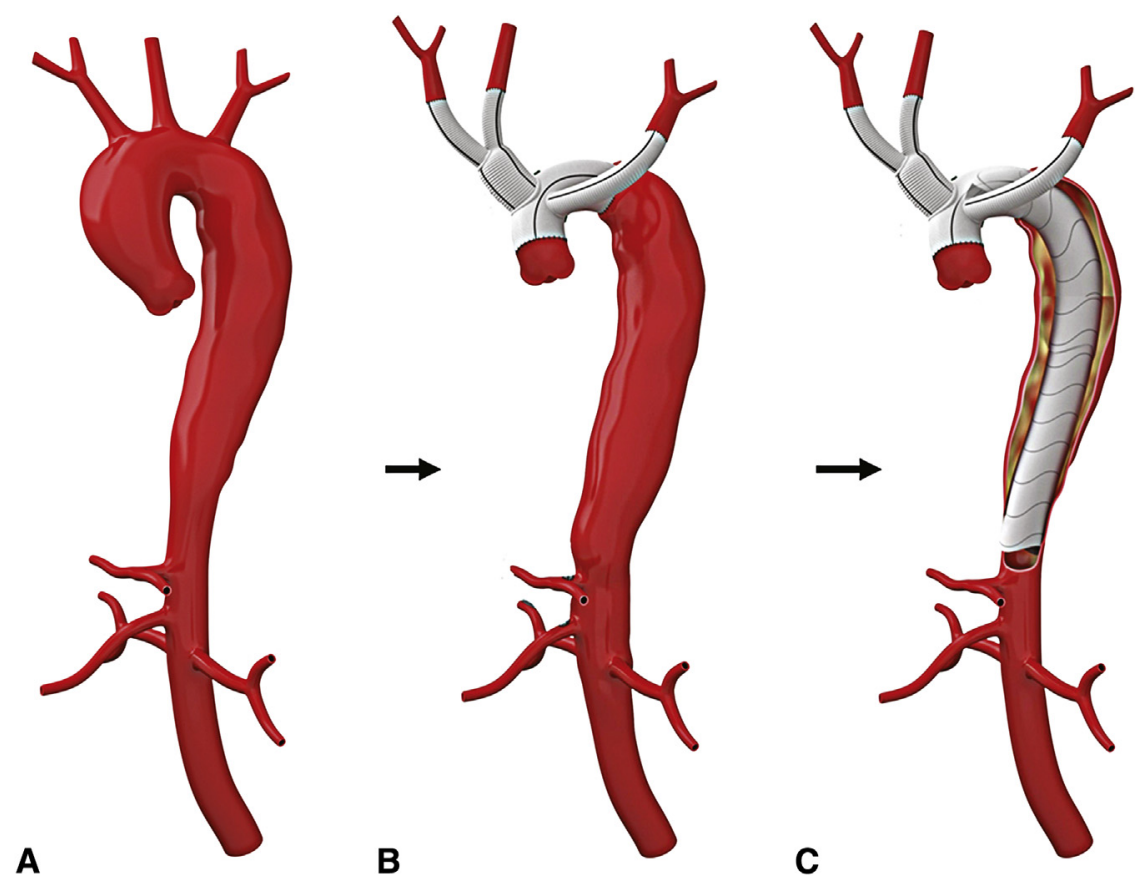

FIGURE 1. Schematic representation of the Lupiae technique. A, Native aorta with TAAAD. B, The ascending aorta and the aortic arch are replaced. The neck vessels are rerouted on the proximal ascending aorta creating a landing zone for TEVAR. C, The residual intimal tear in the descending aorta is excluded deploying 1 or multiple stents landing proximally on the Lupiae graft.

descending aorta. Two patients died of heart failure, one of them despite the implant of a right ventricular assist device. Four patients died of multiorgan failure. One patient had mediastinitis. Reexploration for bleeding was performed in $7.8 \%$ of patients. No new postoperative stroke or spinal cord injury occurred, but 3 patients had transient ischemic attacks. Three patients had urgent TEVAR because of acute malperfusion. One of those patients died of bowel ischemia after the procedure. In total, 80 patients were discharged, and 78 were still potentially eligible for elective TEVAR.

CT of the aorta performed 4 weeks after the operation showed that the false lumen was completely thrombosed in 10 patients, not prevailing on the true lumen, and the diameter of the descending aorta was less than $46 \mathrm{~mm}$. These patients were considered "healed." Fifty patients presented 2 risk factors for delayed aortic expansion; 44 patients presented a patent or partially thrombosed false lumen. This was associated with a descending aorta greater than $46 \mathrm{~mm}$ in 23 patients and to a prevailing false lumen in 21 patients. The remaining 6 patients had an association between a descending aorta greater than $46 \mathrm{~mm}$ and a false lumen prevailing on the true lumen. Those 50 patients were classified as "unstable" and underwent an elective TEVAR within 2 weeks from the scan.

For the remaining 18 patients, only a single risk factor, the presence of a patent or partially thrombosed false lumen, was found. These patients were classified as "stable," and 6 months later, 6 patients presented a completely thrombosed false lumen and were considered healed. The remaining 12 patients still had a patent or partially thrombosed false lumen and underwent TEVAR. The interval between the surgery and the TEVAR was $3.3 \pm 2.1$ months.

In 27 patients, a carotid-subclavian bypass was performed before TEVAR because the LSA was not rerouted intraoperatively. The mean number of patients with endovascular stent-grafts deployed was $1.6 \pm 1$.

The results of TEVAR are presented in Table 3. One patient who underwent urgent TEVAR died. No neurologic or renal complications occurred postoperatively. Complete thrombosis of the false lumen in the thoracic aorta was achieved in 59 of 64 patients $(92.1 \%)$. One patient had a type I endoleak, and 4 patients had a type II endoleak.

The survival curve for patients with a healed false lumen after TAAAD repair and patients who underwent TAAAD repair + TEVAR is depicted in Figure 3. At 1, 4, 8 , and 10 years, the survival was $98.8 \% \pm 1.2 \%$, $98.8 \% \pm 1.2 \%, 93.7 \% \pm 5 \%$, and $62.5 \% \pm 18.4 \%$, respectively. Because the population at risk beyond 8 years was less than $10 \%$ of the initial population, the results beyond that point were less reliable and the curve was cut at that level. In the group of patients with a healed false lumen after TAAAD repair (16 patients), no death occurred during follow-up. In the group of patients who underwent TEVAR after TAAAD repair, the survival at $1,4,8$, and 


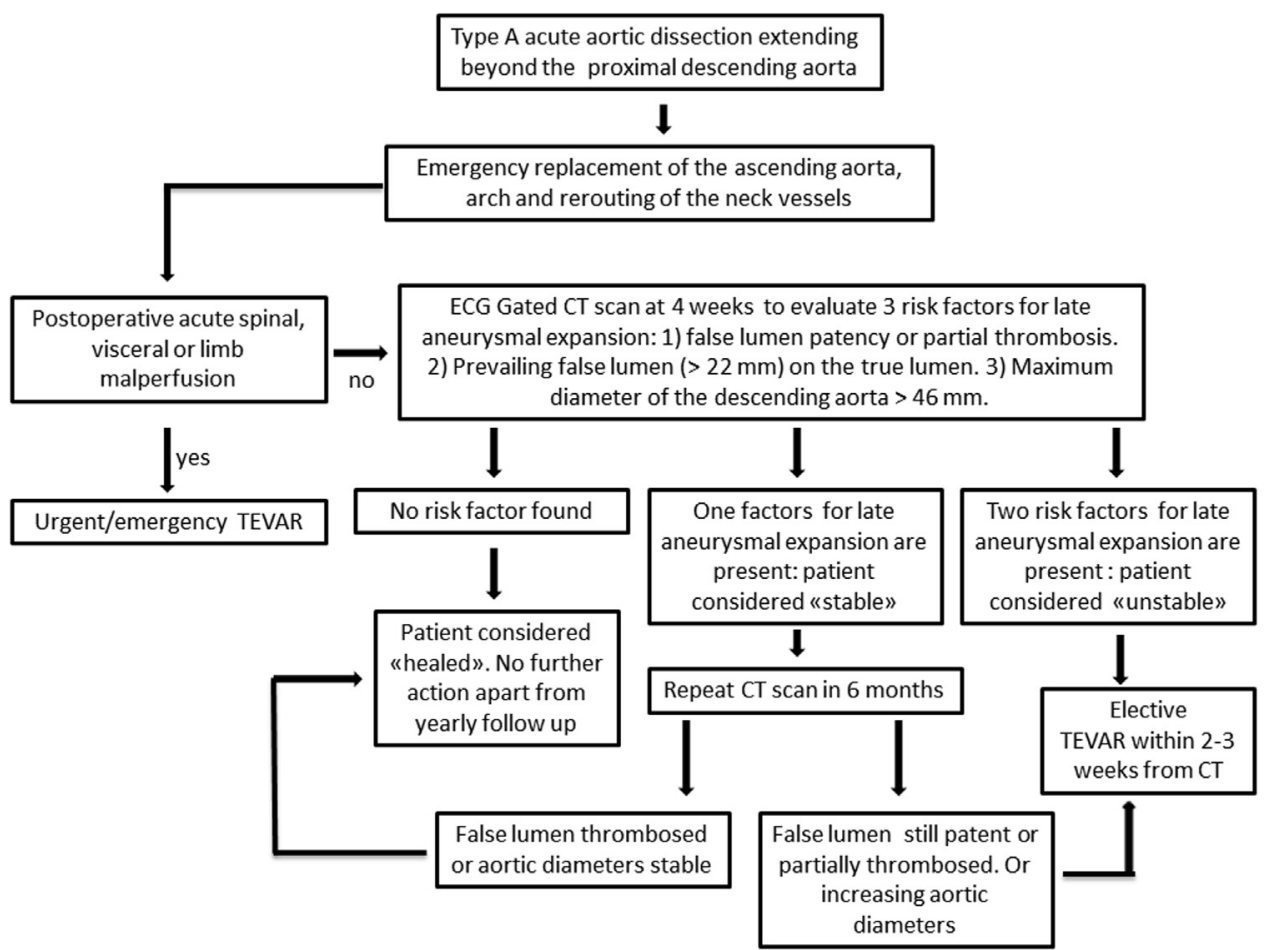

FIGURE 2. Postoperative management of the residual false lumen in patients undergoing TAAAD repair with the Lupiae technique. $C T$, Computed tomography; ECG, electrocardiogram; TEVAR, thoracic endovascular aortic repair.

10 years was $98.4 \% \pm 1.7 \%, 98.4 \% \pm 1.7 \%$, $92.3 \% \pm 7.7 \%$, and $46.1 \% \pm 23.3 \%$, respectively.

The reoperation rate was $1.25 \%$. One patient in the TAAAD repair + TEVAR group underwent reoperation. This patient had Marfan syndrome presenting a type I endoleak with an enlarging and patent false lumen in

TABLE 1. Preoperative characteristics

\begin{tabular}{lc}
\hline Patients & 89 \\
Age, $y$ & $71 \pm 9.1$ \\
Male & $69(77.5 \%)$ \\
Diabetic & $13(14.6 \%)$ \\
COPD & $15(16.8 \%)$ \\
Chronic renal failure & $8(8.9 \%)$ \\
Chest, back, or abdominal pain & $81(91.0 \%)$ \\
Cardiac tamponade & $32(35.9 \%)$ \\
Preoperative CVA & $13(14.6 \%)$ \\
Reoperations & $5(5.6 \%)$ \\
CT findings & \\
$\quad$ Distal extension of the flap & \\
$\quad$ Mid-descending & $8(8.9 \%)$ \\
$\quad$ Distal descending & $10(11.2 \%)$ \\
$\quad$ Abdominal aorta & $71(79.7 \%)$ \\
Transthoracic echocardiographic findings & \\
$\quad$ Mild or moderate AR & $68(76.4 \%)$ \\
$\quad$ Severe AR & $21(26.6 \%)$ \\
Ejection fraction (\%) & $48.6 \pm 12.2$ \\
\hline$A R$ Aortic regurgitation; COPD, chronic obstructive pulmonary & disease; $C T$, \\
computed tomography; $C V A$, cerebrovascular accident.
\end{tabular}

the abdominal aorta. He underwent replacement of the infrarenal aorta and complete visceral debranching with a second Lupiae graft. Subsequently, he underwent endovascular aortic repair with the stent-grafts landing between the distal thoracic stent and the abdominal Lupiae graft. In 4 patients with type II endoleak, the

TABLE 2. Intraoperative procedures

\begin{tabular}{lc}
\hline Patients & 89 \\
Proximal procedures & \\
Isolated AV resuspension & $55(61.8 \%)$ \\
AV resuspension + NCS replacement & $13(14.6 \%)$ \\
Aortic root replacement & $11(12.3 \%)$ \\
Valve sparing root replacement & $10(11.3 \%)$ \\
LSA rerouting & $38(42 \%)$ \\
Position of intimal tear & \\
Ascending aorta & $18(20.2 \%)$ \\
Aortic arch & $56(62.9 \%)$ \\
Descending aorta & $15(16.9 \%)$ \\
CPB time & \\
$\quad$ - with isolated AVR (min) & $112 \pm 19$ \\
$\quad$ - with root surgery (min) & $184 \pm 12$ \\
Crossclamp time & \\
$\quad$ - with isolated AVR (min) & $51 \pm 12$ \\
$\quad$ - with root surgery (min) & $103 \pm 15$ \\
Distal circulatory arrest (min) & $28 \pm 7$ \\
\hline
\end{tabular}

$A V$, Aortic valve; $A V R$, aortic valve replacement; $C P B$, cardiopulmonary bypass; $L S A$, left subclavian artery; $N C S$, noncoronary sinus. 
TABLE 3. Thoracic endovascular aortic repair results

\begin{tabular}{lc}
\hline Patients & 65 \\
Urgent procedure & $3(4.6 \%)$ \\
Elective procedure & $62(95.4)$ \\
In-hospital mortality & $1(1.5 \%)$ \\
Stroke, TIA, paraplegia, paraparesis & 0 \\
AKI & 0 \\
Endoleak type I & $1(1.5 \%)$ \\
Endoleak type II & $4(6.3 \%)$ \\
False lumen thrombosis & $59(92.1 \%)$ \\
\hline AKI, Acute kidney injury; TIA, transient cerebrovascular accident. &
\end{tabular}

management was conservative and the endoleaks resolved spontaneously.

\section{DISCUSSION}

Since 1994, more than 20 studies have evaluated the fate of the residual false lumen after TAAD repair. ${ }^{3-26}$ The presence of a patent or partially thrombosed false lumen has been the strongest risk factor associated with faster aortic growth rates and new aortic aneurysms formation in 15 studies, ${ }^{3-6,11,14,16-18,20-25}$ higher reoperation rates in 8 studies, $3,7,10,11,13,22,24,26$ and worse long-term survival in 6 studies. ${ }^{11,13,17,18,23,26}$

The diameter of the descending aorta has been the second most commonly identified risk factor, associated with faster aortic growth rates and aneurysm formation in 6 studies, $8,12,15,16,18,22$ but less frequently with higher reoperation rates $^{13,22}$ and worse survival. ${ }^{9}$ The evidence supporting a prevailing false lumen as a risk factor is more limited because it was found to be associated with new aneurysm development or faster aortic growth rates in only 3 studies $^{12,19,21}$ and with higher reoperation rates ${ }^{21}$ and worse survival ${ }^{19}$ in 1 study each. The persistence of a nonresected distal intimal tear was the most recently introduced risk factor, first described in $2007^{16}$; it is dependent on high-resolution imaging and associated with

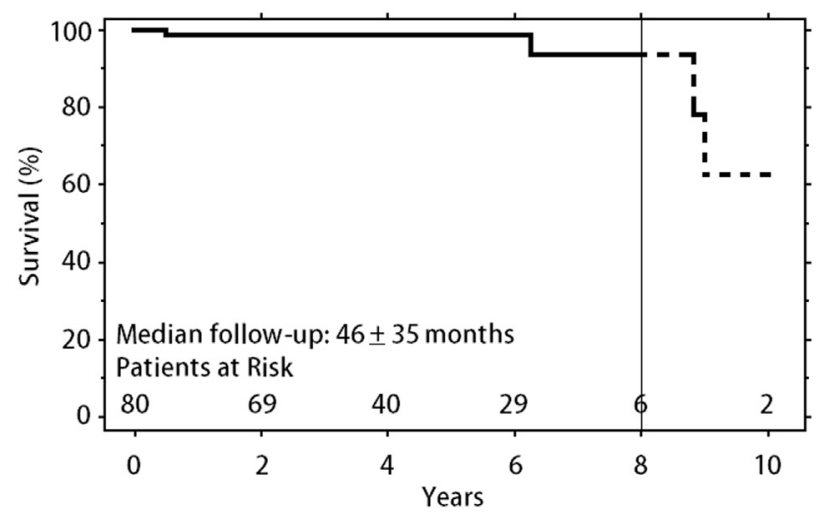

FIGURE 3. Ten-year survival of the entire cohort ( 80 patients); 64 patients underwent TAAAD repair + TEVAR, and 16 patients underwent TAAAD repair only. new aneurysm development or faster aortic growth rates in 2 studies $^{4,5}$ and with higher reoperation rates in 2 studies. ${ }^{7,16}$

By interpreting all this evidence with caution, given the retrospective nature of the studies, we can conclude that in patients with TAAAD extending to the descending aorta, a repair involving the ascending aorta only or the arch is safe and successful in the short-term, but the long-term results of this approach are less predictable. Only the baseline diameters of the descending aorta and sometimes the presence of distal intimal tears can be recognized preoperatively, whereas the thrombosis of the false lumen cannot be predicted.

The mortality associated with redo surgery on the proximal descending aorta is reported to be $12 \%$ in centers that specialize in aortic surgery, ${ }^{28}$ but we argue that in the real world and particularly in patients with a residual false lumen progressing to complex thoracoabdominal aneurysms, palliative medical management is one of the most frequent options.

Aortic debranching is becoming a popular option for chronic aneurisms or chronic aortic dissections, but not yet for TAAAD. ${ }^{29}$ Apart from the Lupiae technique, few small series have been reported in TAAAD. ${ }^{29}$ Our series is the largest and has the longest follow-up in patients with TAAAD. In this new series, we included the initial experience with the Lupiae technique from 2003 to 2006 using custom-made grafts and present the results up to 10 years. Despite the use of different prostheses and a few other technical variations, all patients had an arch replacement and rerouting of the neck vessels on the proximal ascending aorta, creating a proximal Dacron landing zone. We developed a structured follow-up protocol to manage these patients. They were classified as healed or still at risk of delayed aortic expansion. Patients with 2 risk factors underwent TEVAR earlier, only a few weeks from surgery. Patients still presenting a patent false lumen 6 months after the operation also received stents. The mortality associated with TEVAR was $1.5 \%$. In the 80 patients with follow-up, a complete thrombosis of the false lumen occurred spontaneously after the TAAAD repair in 16 patients $(20 \%)$ and was induced by TEVAR in 59 patients $(73.7 \%)$. The 10 -year reoperation rate with this approach was $1.25 \%$. The 8 -year survival was $100 \%$ for healed patients and $92.3 \% \pm 7.7 \%$ for patients receiving TAAAD repair plus TEVAR.

\section{Study Limitations}

One limitation of the study is the lack of sufficient CT scan measurement during the follow-up for a fine comparison of the growth rates of the descending aorta in the various subgroups. Another limitation is the retrospective design and the lack of a large control group undergoing conventional arch replacement. However, no randomized 
trial has been performed on the comparison of different treatments for TAAAD. As a surrogate, the best evidence from a randomized controlled trial is from the Investigation of Stent Grafts in Aortic Dissection XL (INSTEAD-XL) trial, comparing the 5-year results of conservative management with TEVAR for uncomplicated type $\mathrm{B}$ dissections. In patients who were managed conservatively, significantly higher aorta-specific mortality and aortic disease progression rates were identified compared with patients undergoing TEVAR. ${ }^{30}$ Some may argue that type $\mathrm{B}$ dissections and residual dissections after TAAAD repair are not the same entity. This hypothesis was elegantly explored by Krähenbühl and colleagues, ${ }^{7}$ demonstrating that type B dissections tend to involve aneurysms more frequently than residual dissections after TAAAD repairs, but this provided that in those patients operated for TAAAD the intimal tear was excluded, a concept that corresponds to the rationale of the Lupiae technique.

\section{CONCLUSIONS}

The most important message from our experience with the Lupiae technique in patients with TAAAD is that rerouting the neck vessels on the proximal ascending aorta and creating a proximal Dacron landing zone enable better control of the residual false lumen, allowing the prevention or timely management of the development of a dissected aneurysm of the descending aorta with a low-risk procedure. In the current era and independently of any procedural details specific to the Lupiae technique, any surgeon operating on TAAADs and prepared to replace the arch by reimplanting the neck vessels separately should seriously consider rerouting them on the proximal aorta, making an unpredictable outcome more predictable.

\section{References}

1. Kim JB, Chung CH, Moon DH, Ha GJ, Lee TY, Jung SH, et al. Total arch repair versus hemiarch repair in the management of acute DeBakey type I aortic dissection. Eur J Cardiothorac Surg. 2011;40:881-7.

2. Easo J, Weigang E, Hölzl PP, Horst M, Hoffmann I, Blettner M, et al. Influence of operative strategy for the aortic arch in DeBakey type I aortic dissection: analysis of the German Registry for Acute Aortic Dissection Type A. J Thorac Cardiovasc Surg. 2012;144:617-23.

3. Tsai MT, Wu HY, Roan JN, Tsai YS, Hsieh PC, Yang YJ, et al. Effect of false lumen partial thrombosis on repaired acute type A aortic dissection. J Thorac Cardiovasc Surg. February 12, 2014 [Epub ahead of print].

4. Kim YS, Kim JH, Kim JB, Yang DH, Kang JW, Hwang SK, et al. Influence of radiologically evident residual intimal tear on expansion of descending aorta following surgery for acute type I aortic dissection. Korean J Thorac Cardiovasc Surg. 2014;47:6-12.

5. Unosawa S, Hata M, Niino T, Shimura K, Shiono M. Prognosis of patients undergoing emergency surgery for type A acute aortic dissection without exclusion of the intimal tear. J Thorac Cardiovasc Surg. 2013;146:67-71.

6. Larsen M, Bartnes K, Tsai TT, Eagle KA, Evangelista A, Nienaber CA, et al. Extent of preoperative false lumen thrombosis does not influence long-term survival in patients with acute type A aortic dissection. $J$ Am Heart Assoc. 2013;2:e000112.

7. Krähenbühl E, Maksimovic S, Sodeck G, Reineke D, Schoenhoff F, Schmidli J, et al. What makes the difference between the natural course of a remaining type B dissection after type A repair and a primary type B aortic dissection? Eur J Cardiothorac Surg. 2012;41:e110-5.

8. Kim JB, Lee CH, Lee TY, Jung SH, Choo SJ, Lee JW, et al. Descending aortic aneurysmal changes following surgery for acute DeBakey type I aortic dissection. Eur J Cardiothorac Surg. 2012;42:851-6.

9. Evangelista A, Salas A, Ribera A, Ferreira-González I, Cuellar H, Pineda V, et al, Long-term outcome of aortic dissection with patent false lumen: predictive role of entry tear size and location. Circulation. 2012;125:3133-41.

10. Concistrè G, Casali G, Santaniello E, Montalto A, Fiorani B, Dell' Aquila A, et al. Reoperation after surgical correction of acute type A aortic dissection: risk factor analysis. Ann Thorac Surg. 2012;93:450-5.

11. Song SW, Chang BC, Cho BK, Yi G, Youn YN, Lee S, et al. Effects of partial thrombosis on distal aorta after repair of acute DeBakey type I aortic dissection. J Thorac Cardiovasc Surg. 2010;139:841-7.

12. Park KH, Lim C, Choi JH, Chung E, Choi SI, Chun EJ, et al. Midterm change of descending aortic false lumen after repair of acute type I dissection. Ann Thorac Surg. 2009;87:103-8.

13. Fattouch K, Sampognaro R, Navarra E, Caruso M, Pisano C, Coppola G, et al. Long-term results after repair of type A acute aortic dissection according to false lumen patency. Ann Thorac Surg. 2009;88:1244-50.

14. Kimura N, Tanaka M, Kawahito K, Yamaguchi A, Ino T, Adachi H. Influence of patent false lumen on long-term outcome after surgery for acute type A aortic dissection. J Thorac Cardiovasc Surg. 2008;136:1160-6.

15. Almeida AG, Nobre AL, Pereira RA, Costa-Pereira A, Tavares C, Cravino J, et al. Impact of aortic dimensions and pulse pressure on late aneurysm formation in operated type A aortic dissection. A magnetic resonance imaging study. Int J Cardiovasc Imaging. 2008;24:633-40.

16. Zierer A, Voeller RK, Hill KE, Kouchoukos NT, Damiano RJ Jr, Moon MR. Aortic enlargement and late reoperation after repair of acute type A aortic dissection. Ann Thorac Surg. 2007;84:479-86.

17. Sakaguchi G, Komiya T, Tamura N, Kimura C, Kobayashi T, Nakamura H, et al. Patency of distal false lumen in acute dissection: extent of resection and prognosis. Interact Cardiovasc Thorac Surg. 2007;6:204-7.

18. Halstead JC, Meier M, Etz C, Spielvogel D, Bodian C, Wurm M, et al. The fate of the distal aorta after repair of acute type A aortic dissection. J Thorac Cardiovasc Surg. 2007;133:127-35.

19. Song JM, Kim SD, Kim JH, Kim MJ, Kang DH, Seo JB, et al. Long-term predictors of descending aorta aneurysmal change in patients with aortic dissection. J Am Coll Cardiol. 2007;50:799-804.

20. Immer FF, Hagen U, Berdat PA, Eckstein FS, Carrel TP. Risk factors for secondary dilatation of the aorta after acute type A aortic dissection. Eur J Cardiothorac Surg. 2005;27:654-7.

21. Immer FF, Krähenbühl E, Hagen U, Stalder M, Berdat PA, Eckstein FS, et al. Large area of the false lumen favors secondary dilatation of the aorta after acute type A aortic dissection. Circulation. 2005;112(9 Suppl):I249-52.

22. Yeh $\mathrm{CH}$, Chen $\mathrm{MC}$, Wu YC, Wang YC, Chu JJ, Lin PJ. Risk factors for descending aortic aneurysm formation in medium-term follow-up of patients with type A aortic dissection. Chest. 2003;124:989-95.

23. Bernard Y, Zimmermann H, Chocron S, Litzler JF, Kastler B, Etievent JP, et al. False lumen patency as a predictor of late outcome in aortic dissection. Am J Cardiol. 2001;87:1378-82.

24. Fattori R, Bacchi-Reggiani L, Bertaccini P, Napoli G, Fusco F, Longo M, et al. Evolution of aortic dissection after surgical repair. Am J Cardiol. 2000;86:868-72.

25. Barron DJ, Livesey SA, Brown IW, Delaney DJ, Lamb RK, Monro JL. Twentyyear follow-up of acute type A dissection: the incidence and extent of distal aortic disease using magnetic resonance imaging. J Card Surg. 1997;12:147-59.

26. Ergin MA, Phillips RA, Galla JD, Lansman SL, Mendelson DS, Quintana CS, et al. Significance lumen after type A dissection repair. Ann Thorac Surg. 1994;57:820-4.

27. Esposito G, Cappabianca G, Ciano M, Gallo N, Labriola G, Pestrichella V, et al. Mid-term results of the Lupiae technique in patients with De Bakey Type I acute aortic dissection. Eur J Cardiothorac Surg. 2012;42:242-7.

28. Di Bartolomeo R, Berretta P, Petridis FD, Folesani G, Cefarelli M, Di Marco L, et al. Reoperative surgery on the thoracic aorta. J Thorac Cardiovasc Surg. 2013; 145:S78-84.

29. Cao P, De Rango P, Czerny M, Evangelista A, Fattori R, Nienaber C, et al. Systematic review of clinical outcomes in hybrid procedures for aortic arch dissections and other arch diseases. J Thorac Cardiovasc Surg. 2012;144:1286-300.

30. Nienaber C, Kische S, Rousseau H, Eggebrecht H, Rehders T, Kundt G, et al. Endovascular repair of type B aortic dissection: long-term results of the Randomized Investigation of Stent Grafts in Aortic Dissection Trial. Circ Cardiovasc Interv. 2013;6:407-16. 